\title{
Upregulation of Heme Oxygenase-1 in an Animal Model of Takotsubo Cardiomyopathy
}

\author{
Takashi Ueyama, MD; Tetsuya Kawabe, MD*; Takuzo Hano, MD*; \\ Yoshihiro Tsuruo, MD; Kazuki Ueda, MD**; Masao Ichinose, MD**; \\ Hiroko Kimura, $\mathrm{PhD}^{\dagger}$; Ken-ichi Yoshida, $\mathrm{MD}^{\dagger \dagger}$
}

\begin{abstract}
Background: Disturbance of the coronary microcirculation and catecholamine intoxication, which may be responsible for the pathogenesis of takotsubo cardiomyopathy, could trigger an oxidative stress response in the heart.

Methods and Results: Expression and localization of inducible heme oxygenase-1 (HO-1), which is an oxidative stress-related factor in the heart of immobilization stressed (IMO) rats, an animal model of takotsubo cardiomyopathy, were investigated by real-time reverse transcriptase-polymerase chain reaction and in situ hybridization histochemistry and immunohistochemistry. In response to IMO, the levels of HO-1 mRNA in the heart and in the aorta were slightly increased at $90 \mathrm{~min}$, and increased 3 -fold at $3 \mathrm{~h}$ compared with control levels. The signals for HO-1 mRNA were expressed on scatted cells in the myocardium and aortic adventitia. Double fluorescence immunohistochemistry showed that HO-1 immunoreactive cells were also ED1 and ED2 positive, indicating that they were macrophages. The numbers of ED1 and ED2 positive cells were constant, whereas the number of HO-1 positive cells was increased 5-fold at $6 \mathrm{~h}$ compared with control levels. Blocking of $\alpha$ - and $\beta$-adrenoceptors attenuated IMO-induced upregulation of HO-1 mRNA levels in the heart.
\end{abstract}

Conclusions: Emotional stress and a surge of catecholamine upregulate HO-1 in the cardiac and aortic macrophages. (Circ J 2009; 73: 1141-1146)

Key Words: Catecholamines; Emotional stress; Oxidative stress

$\mathbf{T}$ akotsubo cardiomyopathy (also termed transient left ventricular apical ballooning) has been increasingly recognized worldwide. Although the etiology of this syndrome is yet to be clarified, it is considered that disturbance of coronary microcirculation and catecholamine intoxication are the main etiologies, ${ }^{1-3}$ both of which could trigger an oxidative stress response in the heart. An imbalance in the production of reactive oxygen species (ROS) and removal of ROS by antioxidants and scavenger enzymes results in oxidative stress on the cardiovascular system.,5 Acute loss of shear stress, as occurs with ischemia, results in membrane depolarization of endothelial cells, secondary to closure of the adenosine triphosphate sensitive $\mathrm{K}^{+}$(KATP) channels, followed by activation of endothelial nicotinamide adenine dinucleotide phosphate oxidase and ROS production. Oxidative metabolism of catecholamines produces quinones, which react with oxygen to produce ROS5 Increased ROS have diverse toxic effects, such as impairment of the NO-dependent vasodilation, stimulation of leukocyte adhesion molecule and production of inflammatory cytokines,

(Received October 21, 2008; revised manuscript received January 9 , 2009; accepted January 25, 2009; released online April 16, 2009)

Department of Anatomy and Cell Biology, *Center for Educational Research and Development, **Second Department of Internal Medicine, Wakayama Medical University School of Medicine, Wakayama, Department of Forensic Medicine, Juntendo University School of Medicine and Department of Legal Medicine, Graduate School of Medicine, University of Tokyo, Tokyo, Japan

Mailing address: Takashi Ueyama, MD, Department of Anatomy and Cell Biology, Wakayama Medical University School of Medicine, 811-1 Kimiidera, Wakayama 641-8509, Japan. E-mail: tueyama@ wakayama-med.ac.jp

All rights are reserved to the Japanese Circulation Society. For permissions, please e-mail: cj@j-circ.or.jp which leads to further ROS production and oxidative stress.

Heme oxygenase-1 (HO-1) is the inducible isoform of $\mathrm{HO}$, which catalyzes the first and rate-limiting step in heme degradation to produce equimolar quantities of biliverdin, carbon monoxide $(\mathrm{CO})$ and free iron? Biliverdin is subsequently converted to bilirubin via the action of biliverdin reductase, and free iron is promptly sequestered into ferritin. $\mathrm{CO}$ and other toxic agents at low concentrations exert distinctly different effects on physiological and cellular functions. CO leads to vasodilation and inhibition of platelet aggregation? We also reported that exogenous $\mathrm{CO}$ prevented ischemic death of cardiomyogenic cells through L-type $\mathrm{Ca}^{2+}$ channel inhibition? In addition, bilirubin exhibits the highest endogenous antioxidant activity among the constituents of normal human serum? Sequestration of free iron by ferritin lowers the pro-oxidant state of the cell. HO-1dependent release of iron also results in the upregulation of ferritin! ${ }^{10}$ Beneficial effects of HO-1 on the prevention of cardiovascular diseases have been demonstrated. Induction of HO- 1 by pretreatment with hemin significantly decreased the infarction area, which was reversed by the co-administration of a $\mathrm{HO}$ inhibitor in a dose-dependent manner! ${ }^{1}$ Cardiac-specific induction of HO-1 in transgenic mice, ${ }^{12}$ or by using adeno-associated virus ${ }^{13}$ protected against ischemia and reperfusion injury 12 and inhibited postmyocardial infarct remodeling while restoring ventricular function ${ }^{13}$

Therefore, the induction of HO-1 is cytoprotective against oxidation stress in the cardiovascular system.

Immobilization stress (IMO) in the rat is a well-known animal model of emotional stress, which activates the hypothalamic-pituitary-adrenocortical system and the sympathoadrenal system $!^{4}$ We have succeeded in developing a model of this clinical condition in rats ${ }^{15}$ Characteristic 
changes, such as elevation of the ST segment on ECG, the reversible LV apical ballooning on left ventriculography and the induction of immediate early genes in the heart, were antagonized by pretreatment with combined blockade of $\alpha$ - and $\beta$-adrenoceptors, suggesting that enhanced sympathoadrenal outflow is involved in these cardiac changes!6,17 Treatment with estrogen also prevented stress-induced cardiac dysfunction by increasing cardioprotective substances and decreasing sympathoadrenal outflow ${ }^{18}$ In the present study, we focused on the induction and localization HO-1 in an animal model of takotsubo cardiomyopathy.

\section{Methods}

\section{Tissue Preparation}

Male Wistar rats, 6 weeks old, were purchased from Kiwa Lab. Animals (Wakayama, Japan) and housed in a temperature-controlled environment. Experiments were performed after allowing the rats free access to food and water for 1 week. The animals were restrained by securing them on their back to a board using adhesive tape (ie, IMO). Five unrestrained animals served as controls. The rats were decapitated under ether anesthesia at 15, 30, 60, 90 and $120 \mathrm{~min}$ from the start of IMO ( $\mathrm{n}=5$ at each time point). In addition, after IMO for $120 \mathrm{~min}$, a group of animals were returned to their home cages and then killed by decapitation under ether anesthesia at $1,2,3,5$ and $22 \mathrm{~h}$ later $(\mathrm{n}=5$ at each time point). The heart and aorta were rapidly removed from each rat and gently rinsed with saline. The heart sample was cut horizontally at the papillary muscle level and the basal side including the ascending aorta was mounted in OCT compound (Tissue-Tek ${ }^{\circledR}$, Sakura Finetechical, Tokyo, Japan) and frozen using powdered dry ice, while the apex side was fixed in $4 \%$ paraformaldehyde in $0.1 \mathrm{~mol} / \mathrm{L}$ phosphate buffer, $\mathrm{pH} 7.4$ overnight at $4^{\circ} \mathrm{C}$, then cryoprotected in phosphate-buffered saline (PBS) containing $30 \%$ sucrose for 3 days at $4^{\circ} \mathrm{C}$. The frozen samples were stored at $-80^{\circ} \mathrm{C}$ until sectioned and assayed. The aorta was also gently rinsed with saline, and immediately frozen using powdered dry ice within $1 \mathrm{~min}$ after decapitation. Anesthetic, analgesic and tranquilizing drugs were not given during IMO in order to reproduce the clinical manifestations of emotional stress. All animal manipulations were approved by the Wakayama Medical College Animal Care and Use Committee.

\section{Pharmacological Treatment}

An $\alpha 1$-adrenoceptor blocker, prazosin hydrochloride (Sigma, St Louis, MO, USA) and a $\beta 1$-adrenoceptor blocker, metoprolol tartrate (Sigma) were used. The animals were fasted for $24 \mathrm{~h}$ before the experiments. Each drug was dissolved in physiological saline for administrated prior to IMO (prazosin: $1 \mathrm{mg} / \mathrm{kg}$, PO, $45 \mathrm{~min}$ before; metoprolol: $10 \mathrm{mg} / \mathrm{kg}$, IP, $10 \mathrm{~min}$ before). After administration of drug, the rats were exposed to IMO for $120 \mathrm{~min}$, killed and the hearts and aorta were rapidly removed. The heart sample was cut horizontally at the papillary muscle level and mounted in OCT compound (Tissue-Tek) and frozen using powdered dry ice ( $n=4$, for each drug). Controls for the drug studies were treated with the same dosage and schedule of drug administration prior to death, but were not subjected to IMO stress ( $n=4$, for each drug). Drug dosages were based on our previous studies! 16,17

\section{In-Situ Hybridization Histochemistry}

Frozen sections $(6 \mu \mathrm{m})$ were cut by cryostat and thaw- mounted onto silane-coated slides. The probe for detection of HO-1 mRNA was complementary to the nucleotides 276315 of rat HO-1 mRNA: ${ }^{19}$ GCTCTATCTCCTCTTCCAGGGCCGTATAGATATGGTACAA. A computer-assisted homology search revealed no identical sequences in any rat genes in the database (GenBank). In situ hybridization histochemistry (ISH) was performed as previously described ${ }^{17,18}$ The slides were coated with K-5 emulsion (Ilford, Knutsford, UK) diluted 1:2 with water for autoradiography and then exposed for 6-10 weeks at $4^{\circ} \mathrm{C}$. Slides were developed in D-19 (Kodak, Rochester, NY, USA) and the sections were counterstained with hematoxylin-eosin for morphological examinations.

\section{Real-Time Reverse Transcriptase-Polymerase Chain Reaction (RT-PCR)}

Following the preparation of frozen sections of the heart, an additional section of $50 \mu \mathrm{m}$ in thickness was cut by cryostat. Total RNA from these cardiac sections and the segments of aorta were extracted by RNeasy ${ }^{\circledR}$ Mini Kit (QIAGEN, Tokyo, Japan) and digested with RNase freeDNase (QIAGEN). Expression of HO-1 mRNAs was determined by real-time RT-PCR. Primers were made using the following sequences based on the nucleotides 718-979 of rat HO-1 mRNA:19 5'-AAGAGGCTAAGACCGCCTTC-3' (forward), 5'-GCATAAATTCCCACTGCCAC-3' (reverse). As an internal control, we also estimated the expression of rat glyceraldehyde-3 phosphate dehydrogense (GAPDH) mRNA using the following sequences based on the nucleotides 904-1034 of rat GAPDH mRNA:20 5'-AGGTTGTCTCCTGTGACTTC-3' (forward), 5'-CTGTTGCTGTAGCCATATTC-3' (reverse). Total RNA $(0.1 \mu \mathrm{g})$ was converted into cDNA by reverse transcription using random primer $\mathrm{p}(\mathrm{dN}) 6$ and pOligo-p $(\mathrm{T}) 15$ primers and AMV reverse transcriptase (Roche Diagnostics Corp, Indianapolis, IN, USA) in a total reaction volume of $20 \mu$. PCR amplification using a LightCycler instrument was carried out in $20 \mu \mathrm{l}$ of reaction mixture consisting of LightCycler FastStart DNA Master SYBR Green I (Roche Diagnostics GmbH, Penzberg, Germany), $4.0 \mathrm{mmol} / \mathrm{L} \mathrm{MgCl} 2,0.5 \mu \mathrm{mol} / \mathrm{L}$ of each probe, and $2 \mu \mathrm{l}$ of template cDNA in a LightCycler capillary. Relative mRNA in each sample was then quantified automatically by reference to the standard curve constructed each time according to the LightCycler software. The levels of mRNA were calculated with reference to external standard curves constructed by plotting the log number of 10 -fold serial diluted cDNA samples against the respective threshold cycle with the second derivative maximum method. Each product showed a single band corresponding to the estimated molecular size (HO-1 mRNA, 262bp; GAPDH, $309 \mathrm{bp}$ ). Expression of mRNA level in each sample was normalized against its GAPDH mRNA level.

\section{Immunohistochemistry}

Frozen sections $(6 \mu \mathrm{m})$ were cut by cryostat and thawmounted onto silane-coated slides. Sections were incubated with $3 \% \mathrm{H}_{2} \mathrm{O}_{2}$ in distilled water for $20 \mathrm{~min}$ to quench the endogenous peroxidase activity and after rinsing twice with PBS, they were incubated with the primary antiserum against HO-1 (rabbit polyclonal, SPA-895) diluted 1:1,000 with $0.1 \mathrm{~mol} / \mathrm{L}$ PBS containing $5 \%$ normal goat serum and $0.3 \%$ Triton $\mathrm{X}-100$ or monoclonal antibody against macrophage, ED1 (CD68) and ED2 (CD163) (mouse monoclonal, Affinity Bioreagents, Golden, CO, USA) diluted 1:200 with $0.1 \mathrm{~mol} / \mathrm{L} \mathrm{PBS}$ containing $5 \%$ normal goat serum for $48 \mathrm{~h}$ at 


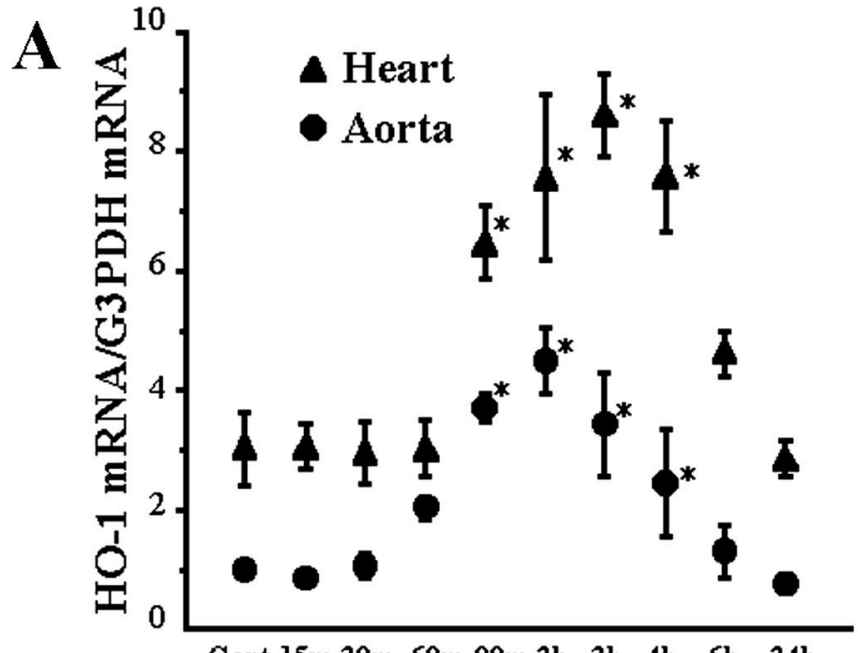

Cont $15 \mathrm{~m} \mathrm{30m} \mathrm{60m} \mathrm{90m} \mathrm{2h} \mathrm{3h} \mathrm{4h} \mathrm{6h} 24 \mathrm{~h}$
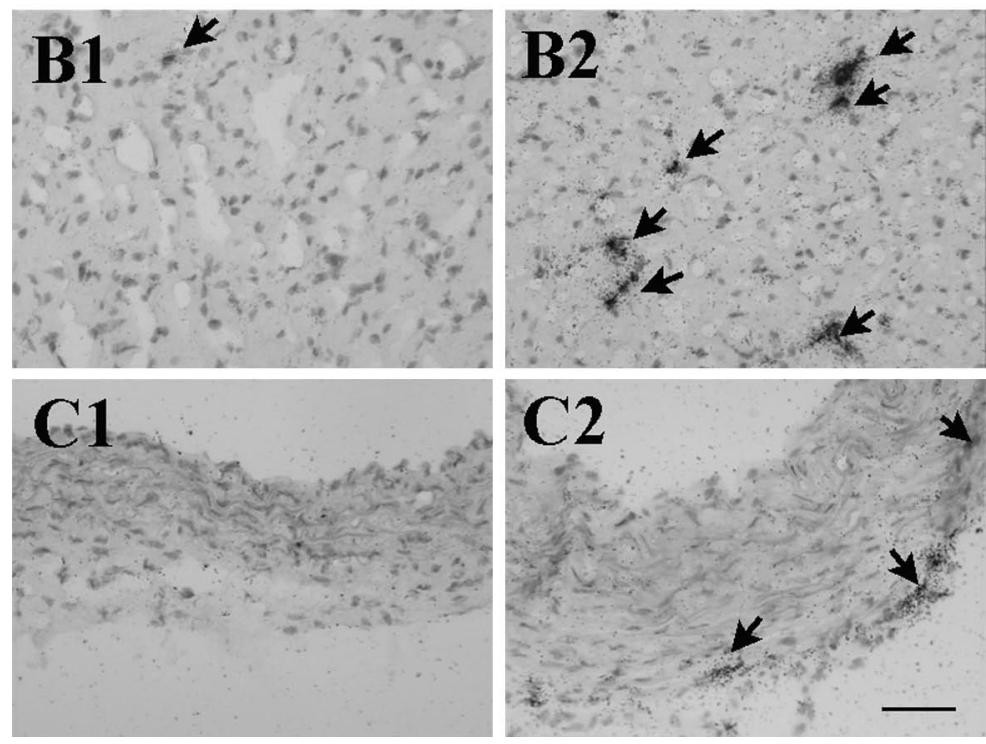

Figure 1. Expression and localization of heme oxygenase-1 (HO-1) mRNA in the heart and aorta in response to immobilization stress. (A) Time course of relative HO$1 \mathrm{mRNA}$ levels in the heart (closed triangle) and aorta (closed circle) evaluated by real-time reverse transcriptase-polymerase chain reaction. ${ }^{*} \mathrm{P}<0.01$ compared with control. The levels of HO-1 mRNA are slightly increased at $90 \mathrm{~min}$, and have increased 3 -fold at $3 \mathrm{~h}$ compared with control levels. They gradually decrease and return to the control level at $24 \mathrm{~h}$. (B,C) Light photomicrographs of the heart (B) and aorta (C) at baseline (B1,C1) and $3 \mathrm{~h}$ (B2, C2). In situ hybridization histochemistry shows the scattered signals for HO-1 mRNA in the myocardium and adventitia of the aorta (arrow). Increased HO-1 mRNApositive cells can be seen $(\mathbf{B 2}, \mathbf{C 2})$. Scale bar $=30 \mu \mathrm{m}$. $4^{\circ} \mathrm{C}$. Omission of the primary or secondary antibody completely eliminated all immunoreactive staining. After washing in PBS, the sections were incubated with the secondary antibody (biotinylated horse anti-mouse IgG, or biotinylated goat anti-rabbit IgG, Vector Laboratories, Burlingame, CA, USA) diluted 1:200 in PBS for $1 \mathrm{~h}$ at $37^{\circ} \mathrm{C}$. After rinsing twice with $\mathrm{PBS}$, they were incubated with avidin-biotin-horseradish peroxide complex (ABC Elite kit, Vector Laboratories) for $1 \mathrm{~h}$ at $37^{\circ} \mathrm{C}$. After washing in $0.05 \mathrm{~mol} / \mathrm{L}$ Tris- $\mathrm{HCl}$ buffer, $\mathrm{pH} 7.6$, immunoreactions were visualized by incubation in $0.05 \mathrm{~mol} / \mathrm{L}$ Tris- $\mathrm{HCl}$ buffer, $\mathrm{pH}$ 7.6, containing $0.02 \% 3$, 3'-diaminobenzidine tetrahydrochloride (DAB) and $0.005 \% \mathrm{H}_{2} \mathrm{O}_{2}$ for $2-5 \mathrm{~min}$. The sections were counterstained with hematoxylin.

All cell counts were performed on coded slides by a single observer who was unaware of the treatments. The analysis was performed using a light microscope (Nikon Y-FL; Nikon Corp, Tokyo, Japan) connected to a digital camera DXM1200 (Nikon). The digitized images were transferred to a Dell personal computer, and immunoreactive cells were counted using anatomical mapping and tracing software (Neurolucida ${ }^{\circledR}$ with NeuroExplorer ${ }^{\mathrm{TM}}$ Ver 5.05.4; MicroBright Field, Inc, Williston, VT, USA). In short, the border of the left ventricular wall was traced and immuno- reactive cells within the area were marked on the computer. The density of immunoreactive cells was calculated and expressed as cell number per $1 \times 10^{4} \mu \mathrm{m}^{2}$.

For double-fluorescence immunohistochemistry, sections were incubated simultaneously with the primary antiserum against HO-1 (rabbit polyclonal, SPA-895) diluted 1:1,000 and monoclonal antibody against macrophage, ED1 (CD68) and ED2 (CD163) (mouse monoclonal, Affinity Bioreagents) diluted 1:200 with $0.1 \mathrm{~mol} / \mathrm{L}$ PBS containing $5 \%$ normal goat serum. After rinsing twice with PBS, sections were incubated with the secondary antibody (biotinylated goat anti-rabbit IgG, Vector Laboratories) diluted 1:200 in PBS for $1 \mathrm{~h}$ at $37^{\circ} \mathrm{C}$. Finally, they were incubated in $1: 100$ dilution of Texas-Red avidin D (Vector Laboratories), simultaneously with 1:100 dilution of fluorescein isothiocyanate-conjugated goat anti-mouse IgG antibody (Jackson ImmunoResearch Lab, West Groove, PA, USA) in $0.1 \mathrm{~mol} / \mathrm{L}$ PBS containing 5\% normal goat serum and $0.3 \%$ Triton $\mathrm{X}-100$ for $1 \mathrm{~h}$ at $37^{\circ} \mathrm{C}$. They were rinsed twice with PBS, and coverslipped with an anti-fade solution (VECTASHIELD, Vector Laboratories).

\section{Statistical Analysis}

Data are shown as mean \pm SEM. Statistical analysis was 

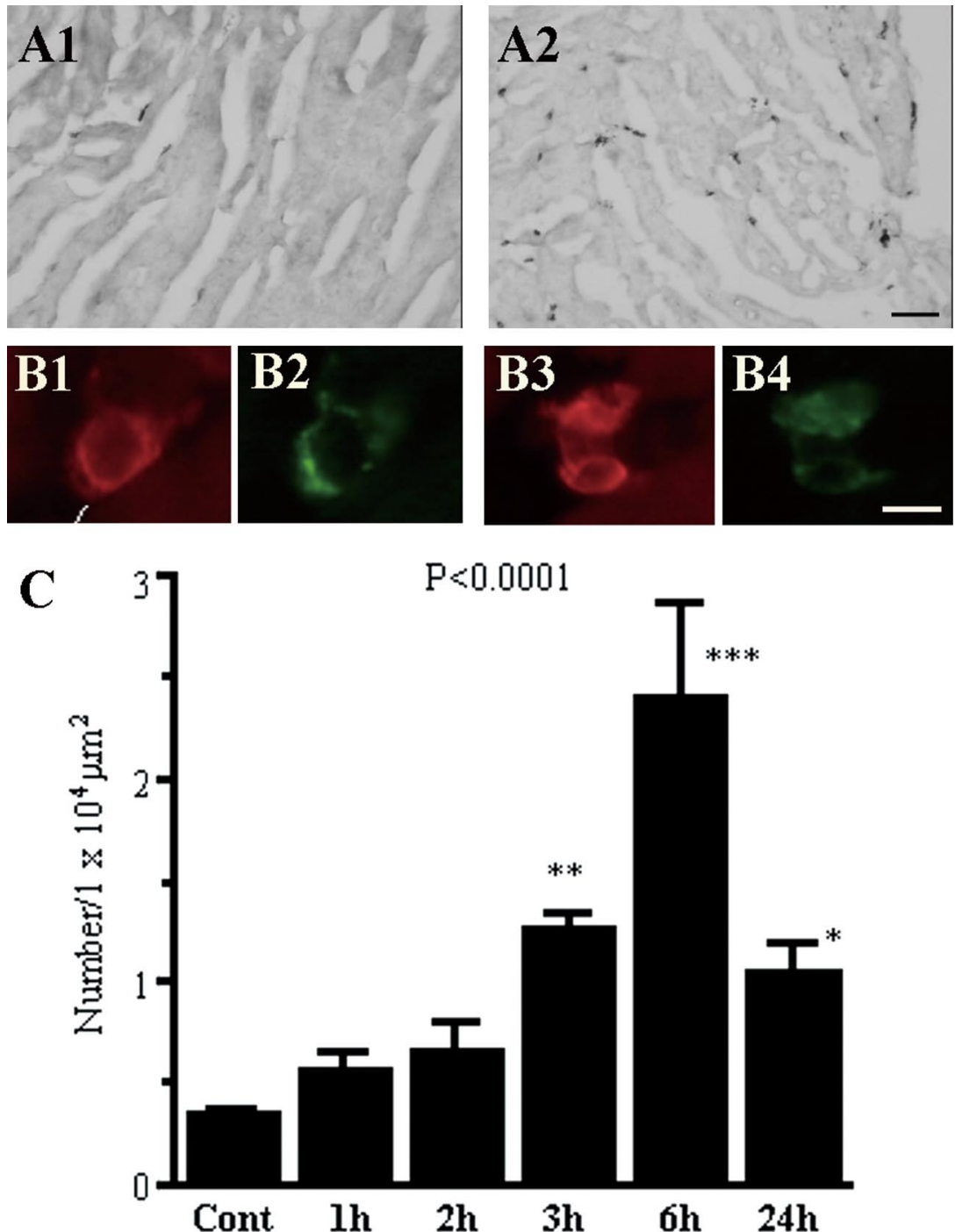

Figure 2. Expression and localization of immunoreactivity for heme oxygenase-1 (HO1) in the heart. (A) Light photomicrographs of the heart at baseline (A1) and 6h (A2). HO-1 immunoreactive cells can be seen in the control section (A1), and have increased 5-fold at $6 \mathrm{~h}$ compared with control levels in the corresponding cells, as shown by in situ hybridization (A2, C). $* \mathrm{P}<0.05, * * \mathrm{P}<0.01$, $* * * \mathrm{P}<0.001$ compared with control. Double-fluorescence immunohistochemistry shows HO-1 immunoreactive cells (B1 and B3, respectively, colored in red) are both ED1- and ED2-positive (B2 and B4, respectively, colored in green), indicating they are macrophages. Scale bars, $30 \mu \mathrm{m}$ (A) and $5 \mu \mathrm{m}(\mathbf{B})$. performed by 1-way, 2-repeated-measures ANOVA, followed by Fisher's protected least significant difference test using StatView software (Abacus Concepts, Berkeley, CA, USA). Differences were considered significant at $\mathrm{P}<0.05$. For details, see Figures 1-4.

\section{Results}

The levels of HO-1 mRNA in the heart and in the aorta were slightly increased at $90 \mathrm{~min}$, and increased 3 -fold at $3 \mathrm{~h}$ compared with control levels. They gradually decreased and returned to the control level at $24 \mathrm{~h}$ (Figure 1A). ISH demonstrated signals for HO-1 mRNA in scattered cells in the myocardium and in the adventitia of the aorta (Figures 1B, C). An increased number of HO-1 mRNA-positive cells was also observed (Figures 1B, C).

HO-1 immunoreactive cells were observed in the control section (Figure 2A1), but the number of HO-1 immunoreactive cells had increased 5-fold at $6 \mathrm{~h}$ compared with control levels in the corresponding cells as shown by ISH (Figures 2A2, C). Omission of the primary antibody completely eliminated the immunoreactivity (data not shown). Double-fluorescence immunohistochemistry showed that HO-1 immunoreactive cells (Figures 2B1, B3, respectively, colored in red) were ED1- and ED2-positive (Figures 2B2, B4, respectively, colored in green), indicating that they were macrophages. The numbers of ED1- and ED2-positive cells were constant (Figures 3A-D).

IMO-induced increased levels of HO-1 mRNA in the heart were significantly attenuated by pretreatment with an $\alpha 1$ - or $\beta 1$-adrenoceptor blocker (Figure 4A), whereas in the aorta it was not significant (Figure 4B).

\section{Discussion}

Oxidative stress is strongly implicated in the progression of cardiovascular diseases such as atherosclerosis, acute coronary syndrome, cardiac hypertrophy and heart failure ? $^{23}$ $\mathrm{HO}-1$ is considered to be counteractive against oxidative stress $^{24}$ In our animal model of emotional stress-induced takotsubo cardiomyopathy, the upregulation of HO-1 observed in cardiac and aortic macrophages was antagonized by blockers of adrenoceptors.

Recently, Nef et al used microarray analysis to report the systemic expression profiles of cardiac genes in patients with takotsubo cardiomyopathy, which indicated that oxidative stress related transcriptional factor, NF-E2-related factor (Nrf2)-induced genes and genes involved in protein 

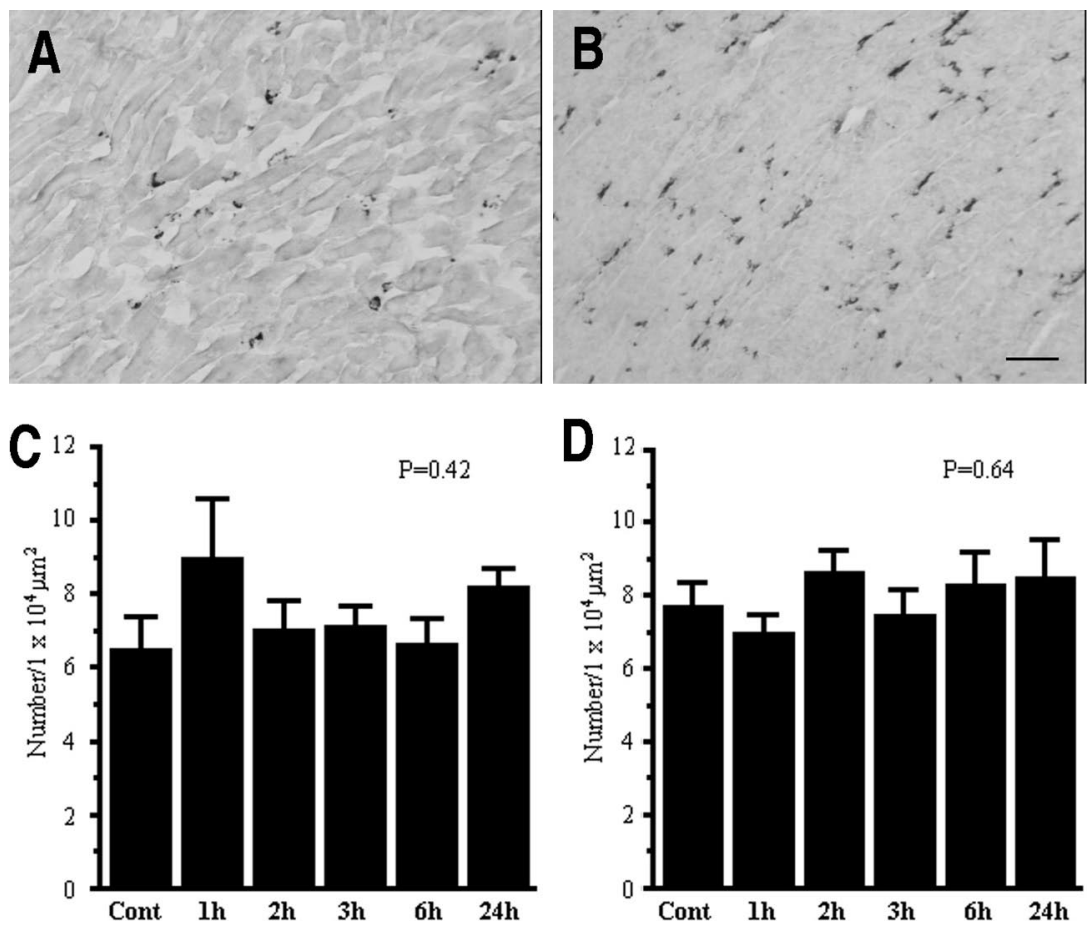

Figure 3. Expression and localization of immunoreactivity for ED-1 (A,C) and ED-2 $(\mathbf{B}, \mathbf{D})$ in the heart. (A,B) Light photomicrographs of the heart at baseline. The numbers of ED1- and ED2-positive cells are constant $(\mathbf{C}$, D). Scale bar $=30 \mu \mathrm{m}(\mathbf{A}, \mathbf{B})$. biosynthesis were upregulated in the acute phase $25 \mathrm{We}$ previously observed a prominent increase in immediate early genes/transcriptional factors such as c-fos, c-jun and erg-1 (NGFI-A) in the emotionally stressed heart! ${ }^{17}$ In the present study, we found that HO-1, an oxidative stress-related gene, was also upregulated in cardiac and aortic macrophages in response to emotional stress. Our experimental data using an animal model confirm the clinical findings in patients with takotsubo cardiomyopathy.

Expression of HO-1 in the macrophages has been reported in association with atherosclerotic lesions and ischemic heart disease (IHD). The number of macrophages is increased in the heart of patients with IHD as compared with control and dilated cardiomyopathy patients ${ }^{26}$ Ischemia-reperfusion also induces HO-1 in the monocytes/macrophages and myofibroblasts in the rat heart. ${ }^{11}$ Prominent increases in the levels of catecholamines are a well-known finding in patients with takotsubo cardiomyopathy ${ }^{1-3}$ and in rats subjected to IMO 15 Blocking of adrenoceptors prevents IMO-induced cardiac dysfunction and gene expression $!^{15-17}$ Taken together, our results show that emotional stress and a surge of catecholamines upregulate the expression of HO-1 in cardiac and aortic macrophages.

Several lines of evidences indicate that macrophages express both $\alpha$ - and $\beta$-adrenoceptors and are reactive to catecholamines, followed by HO-1 produciton 27,28 In this study, pretreatment with an $\alpha$ - or $\beta$-blocker antagonized the IMO-induced up-egulation of HO-1 mRNA in the heart, indicating that activating both $\alpha$ - and $\beta$-adrenoceptors is involved in the induction of HO-1 mRNA in macrophages. Attenuation of the IMO-induced increase of HO-1 mRNA with $\alpha$ or $\beta$-blockers was also observed in the aorta, though the significant differences were not detected. We think relatively lower expression of HO-1 mRNA in the aorta may be associated with a larger standard deviation, resulting in lack of statistical difference. It is also considered that induction of HO-1 in macrophages is mediated by a product of lipid
A

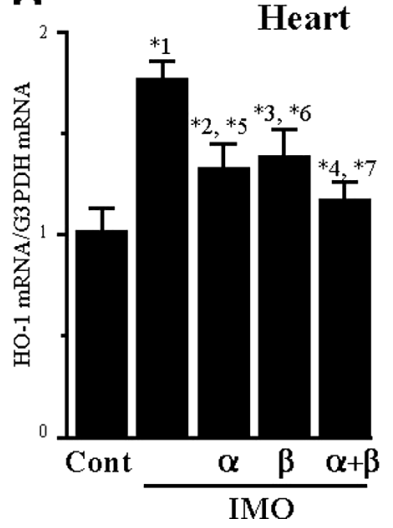

B

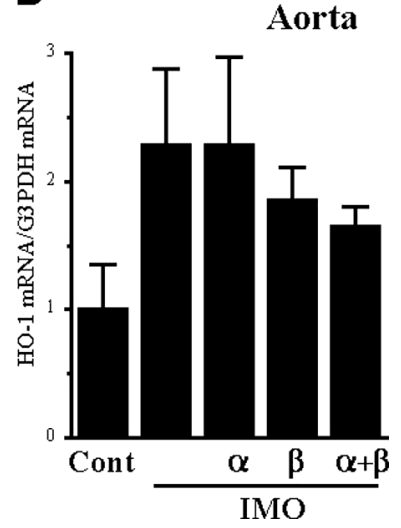

Figure 4. Evaluation of heme oxygenase-1 (HO-1) mRNA in the heart and in the aorta in response to immobilization stress (IMO) with pretreatment with an $\alpha 1$-adrenoceptor blocker, prazosin, or $\beta 1$-adrenoceptor blocker, metoprolol. The IMO-induced increased levels of HO-1 mRNA are significantly attenuated by pretreatment with $\alpha 1$ adrenoceptor blocker or $\beta 1$-adrenoceptor blocker in the heart (A), but in the aorta the significance is not observed $(\mathbf{B}) . * 1, \mathrm{P}<0.01$, Cont vs IMO; $* 2$, NS, Cont vs $\alpha+\mathrm{IMO} ; * 3, \mathrm{P}<0.05$, Cont vs $\beta+\mathrm{IMO} ; 4$, NS, Cont vs $\alpha+\beta+$ IMO; $* 5, \mathrm{P}<0.05$, IMO vs $\alpha+\mathrm{IMO} ; * 6, \mathrm{P}<0.05$, IMO vs $\beta+\mathrm{IMO} ; * 7, \mathrm{P}<0.01$, IMO vs $\alpha+\beta+\mathrm{IMO}$.

peroxidation and a chemical mediator of the oxidative response array, 4-hydroxynonenal (HNE) and oxidative stress related transcriptional factor, Nrf229,30 Because our preliminary data indicate that plasma HNE levels are increased in response to IMO, the HNE-Nrf2 mediated mechanism may be involved in HO-1 induction in cardiac and aortic macrophages. Possible differences in HO-1 expression, especially between the apical and basal segments of the heart should be investigated in a further study.

The heme molecule interacts with various inactive apo- 
heme molecules, giving rise to functional heme proteins including hemoglobin, myoglobin, cytochromes, NO synthase and cyclooxygenase. These heme proteins in cells and heme-apoprotein binding may become unstable under conditions of stress. However, in the acute phase of takotsubo cardiomyopathy, there is only a small release of cardiac enzymes into the circulation!-3 Myocardial damage and bleeding are observed less in biopsy specimens taken from cases of takotsubo cardiomyopathy ${ }^{1-3}$ or from the hearts of stressed rats. Thus, release of heme from myocardial cells and aortic cells may also be limited. In addition, increased immunoreactive HO-1 was observed after cessation of IMO, so we consider that upregulated HO-1 in response to IMO may not be effective for ameliorating the initial oxidative stress. Instead, cardiac and aortic tissues acquire resistance to further oxidative stress. In fact, artificial introduction of HO-1 into cardiac cells protects against ischemia and reperfusion injury!1-13 The quick recovery of cardiac function and low recurrence in cases of takotsubo cardiomyopathy might be associated with acquired resistance in response to the first attack.

In conclusion, cardiac and aortic macrophages upregulate HO-1 in response to emotional stress and the surge of catecholamines as an endogenous defense mechanism against oxidative stress.

\section{Statement of Responsibility}

The authors had full access to the data and take responsibility for its integrity. All authors have read and agree to the manuscript as written.

\section{References}

1. Lyon AR, Rees PS, Prasad S, Poole-Wilson PA, Harding SE. Stress (Takotsubo) cardiomyopathy: A novel pathophysiological hypothesis to explain catecholamine-induced acute myocardial stunning. Nat Clin Pract Cardiovasc Med 2008; 5: 22-29.

2. Akashi YJ, Goldstein DS, Barbaro G, Ueyama T. Takotsubo cardiomyopathy: A new form of acute, reversible heart failure. Circulation 2008; 118: $2754-2762$.

3. Kume T, Kawamoto T, Okura H, Toyota E, Neishi Y, Watanabe N, et al. Local release of catecholamines from the hearts of patients with tako-tsubo-like left ventricular dysfunction. Circ J 2008; 72: 106108.

4. Crimi E, Ignarro LJ, Napoli C. Microcirculation and oxidative stress. Free Radic Res 2007; 41: 1364-1375.

5. Dhalla KS, Rupp H, Beamish RE, Dhalla NS. Mechanisms of alterations in cardiac membrane $\mathrm{Ca}^{2+}$ transport due to excess catecholamines. Cardiovasc Drugs Ther 1996; 10: 231-238.

6. Immenschuh S, Schröder H. Heme oxygenase-1 and cardiovascular disease. Histol Histopathol 2006; 21: 679-685.

7. Sammut IA, Foresti R, Clark JE, Exon DJ, Vesely MJ, Sarathchandra $\mathrm{P}$, et al. Carbon monoxide is a major contributor to the regulation of vascular tone in aortas expressing high levels of haeme oxygenase-1. Br J Pharmacol 1998; 125: 1437-1444.

8. Uemura K, Adachi-Akahane S, Shintani-Ishida K, Yoshida K. Carbon monoxide protects cardiomyogenic cells against ischemic death through L-type $\mathrm{Ca}^{2+}$ channel inhibition. Biochem Biophys Res Commun 2005; 334: 661-668.

9. Gopinathan V, Miller NJ, Milner AD, Rice-Evans CA. Bilirubin and ascorbate antioxidant activity in neonatal plasma. FEBS Lett 1994; 349: $197-200$.

10. Vile GF, Tyrrell RM. Oxidative stress resulting from ultraviolet A irradiation of human skin fibroblasts leads to a heme oxygenasedependent increase in ferritin. J Biol Chem 1993; 268: 14678-14681.

11. Hangaishi M, Ishizaka N, Aizawa T, Kurihara Y, Taguchi J, Nagai
$\mathrm{R}$, et al. Induction of heme oxygenase- 1 can act protectively against cardiac ischemia/reperfusion in vivo. Biochem Biophys Res Commun 2000; 279: 582-588.

12. Yet SF, Tian R, Layne MD, Wang ZY, Maemura K, Solovyeva M, et al. Cardiac-specific expression of heme oxygenase-1 protects against ischemia and reperfusion injury in transgenic mice. Circ Res 2001; 89: $168-173$.

13. Liu X, Pachori AS, Ward CA, Davis JP, Gnecchi M, Kong D, et al. Heme oxygenase-1 (HO-1) inhibits postmyocardial infarct remodeling and restores ventricular function. FASEB J 2006; 20: 207-216.

14. Kvetnansky R, Pacak K, Fukuhara K, Viskupic E, Hiremagalur B, Nankova B, et al. Sympathoadrenal system in stress: Interaction with the hypothalamic-pituitary-adrenocortical system. Ann NY Acad Sci 1995; 771: $131-158$.

15. Ueyama T. Emotional stress-induced Tako-tsubo cardiomyopathy: Animal model and molecular mechanism. Ann NY Acad Sci 2004; 1018: $437-444$.

16. Ueyama T, Kasamatsu K, Yamamoto K, Yamamoto K, Tsuruo Y, Nishio I. Emotional stress induces transient left ventricular hypo-contraction in the rat via activation of cardiac adrenoceptors: A possible animal model of tako-tsubo cardiomyopathy. Circ J 2002; 66: 712 713.

17. Ueyama T, Yoshida K, Senba E. Emotional stress induces expression of immediate early genes in rat heart via activation of $\alpha$ - and $\beta$-adrenoceptors. Am J Physiol Heart Circ Physiol 1999; 277: H1553H1561.

18. Ueyama T, Ishikura F, Matsuda A, Asanuma T, Ueda K, Ichinose M, et al. Chronic estrogen supplementation following ovariectomy improves the emotional stress-induced cardiovascular responses by indirect action on the nervous system and by direct action on the heart. Circ J 2007; 71: 565-573.

19. Shibahara S, Muller R, Taguchi H, Yoshida T. Cloning and expression of cDNA for rat heme oxygenase. Proc Natl Acad Sci USA 1985; 82: 7865-7869.

20. Piechaczyk M, Blanchard JM, Marty L, Dani C, Panabieres F, El Sabouty S, et al. Post-transcriptional regulation of glyceraldehyde-3phosphate-dehydrogenase gene expression in rat tissues. Nucleic Acids Res 1984; 12: 6951-6963.

21. Egashira Y. Clinical importance of endothelial function in arteriosclerosis and ischemic heart disease. Circ J 2002; 66: 529-533.

22. Ottaviano FG, Handy DE, Loscalzo J. Redox regulation in the extracellular environment. Circ J 2008; 72: 1-16.

23. Masano T, Kawashima S, Toh R, Satomi-Kobayashi S, Shinohara M, Takaya $\mathrm{T}$, et al. Beneficial effects of exogenous tetrahydrobiopterin on left ventricular remodeling after myocardial infarction in rats: The possible role of oxidative stress caused by uncoupled endothelial nitric oxide synthase. Circ J 2008; 72: 1512-1519.

24. Applegate LA, Luscher P, Tyrrell RM. Induction of heme oxygenase: A general response to oxidant stress in cultured mammalian cells. Cancer Res 1991; 51: 974-978.

25. Nef HM, Möllmann H, Troidl C, Kostin S, Böttger T, Voss S, et al. Expression profiling of cardiac genes in Tako-Tsubo cardiomyopathy: Insight into a new cardiac entity. J Mol Cell Cardiol 2008; 44: 395404.

26. Azzawi M, Kan SW, Hillier V, Yonan N, Hutchinson IV, Hasleton PS. The distribution of cardiac macrophages in myocardial ischaemia and cardiomyopathy. Histopathology 2005; 46: 314-319.

27. Gosain A, Muthu K, Gamelli RL, DiPietro LA. Norepinephrine suppresses wound macrophage phagocytic efficiency through alpha- and beta-adrenoreceptor dependent pathways. Surgery 2007; 142: 170179.

28. Sun J, Kim SJ, Park MK, Kim HJ, Tsoy I, Kang YJ, et al. Selective activation of adrenergic beta1 receptors induces heme oxygenase 1 production in RAW264.7 cells. FEBS Lett 2005; 579: 5494-5500.

29. Ishii T, Itoh K, Ruiz E, Leake DS, Unoki H, Yamamoto M, et al. Role of Nrf2 in the regulation of CD36 and stress protein expression in murine macrophages: Activation by oxidatively modified LDL and 4-hydroxynonenal. Circ Res 2004; 94: 609-616.

30. Ueda K, Ueyama T, Yoshida K, Kimura H, Ito T, Shimizu Y, et al. Adaptive HNE-Nrf2-HO1 pathway against oxidative stress is associated with acute gastric mucosal lesions. Am J Physiol Gastrointest Liver Physiol 2008; 295: G460-G469. 